\section{Teaching Opportunity Cost in an Emissions Permit Experiment}

\section{Abstract}

This paper describes an individual choice experiment that can be used to teach students how to correctly account for opportunity costs in production decisions. Students play the role of producers that require a fuel input and an emissions permit for production. Given fixed market prices, they make production quantity decisions based on their costs. Permits have a constant price throughout the experiment. In one treatment, students have to purchase both a fuel input and an emissions permit for each production unit. In a second treatment, they receive permits for free and any unused permits are sold on their behalf at the permit price. If students correctly incorporate opportunity costs, they will have the same supply function in both treatments. This experiment motivates classroom discussion of opportunity costs and emission permit allocation under cap and trade schemes. The European Union Emissions Trading Scheme (EU ETS) provides a relevant example for classroom discussion, as industry earned significant "windfall profits" from free allocation of emissions permits in the early phases of the program.

\section{Introduction}

The notion of opportunity cost is pervasive in economics, and it is one of the first 'principles' encountered by students in an introductory microeconomics class. A typical example is given in terms of the alternative earnings potential of a self-employed manager or farmer, where the accounting profit of the business can be converted into an economic loss when the opportunity cost of self-employment is considered. Most students readily agree with the reasoning in this example, and yet experience with simulations of actual decisions reveals that many of them fail to incorporate opportunity costs into other decisions correctly. This paper presents a class experiment in an environmental frame, in which inter-personal earnings comparisons can be used to show that those with low earnings can improve their earnings dramatically by basing decisions on a correct cost measure that includes opportunity cost. The key insight is that if tradable 'permits' for greenhouse gases or other emissions are provided free to producers, in a process called 'grandfathering,' then the producer's cost should include the opportunity cost of the permits, which is what they can sell for in an open market. ${ }^{2}$ This experiment takes about 30 minutes to run, and about 15 minutes should be allocated to discussion. It can be used for courses in introductory and intermediate microeconomics, and for courses in environmental economics.

\section{Procedures}

The experiment can be run by hand, by providing students with a table of variable 'fuel' costs for each of their capacity units, and by giving them endowments of permits and telling them what unused permits can be sold for in an external permit market. Then students decide whether or not to operate each of their capacity units, at a market price for the product that is announced by the instructor. The process can be repeated several times with different market prices, to obtain points on a supply function, and earnings can be compared so that students can see that the person with the highest earnings had a supply function that is shifted up due the opportunity cost of the grandfathered permits being 'built in'. Instructions for the hand-run version can be brief:

You are a producer with three capacity units, shown in column (1) of Table 1. You require a fuel input and an emissions 'permit' to produce each unit, and if you do produce a unit, you will sell the output at a price which can be entered for each of your three capacity units in column (2) when it is announced each round. For any unit that you decide to produce, you will incorporate a fuel cost shown in column (3). The first unit costs $\$ 1$ to operate (think of these numbers in terms of millions of dollars). The second capacity unit costs $\$ 3$ to operate, and the third costs $\$ 5$ to operate. You have been given, free of charge, three permits that must be used or sold in this production period, i.e. no banking of permits for future periods is allowed. You indicate your permit use decisions for each capacity unit by circling a 0 or a 1 in column (4). Any unused permits will be automatically sold in a national emissions permit market for a price of \$3. If you use a permit, you receive the difference between price and fuel cost, which can be entered in column (5). Your earnings for the period consist of the sum of the difference between price and cost in column (5), plus $\$ 3$ for any of your unused permits. 
For the hand run version, the instructor will want to copy and distribute earnings tables for a number of periods, and to make a template for graphing supply functions over a range of prices from 1 to 9 . To avoid indifference, use prices in 50 -cent increments, e.g. a randomly ordered mix of $(\$ 1.50, \$ 2.50, \$ 3.50, \ldots . \$ 8.50)$. Decision tables should be copied in advance and distributed when the instructions are read aloud.

Table 1 Decision sheet for production period

\begin{tabular}{lllll}
\hline $\begin{array}{l}\text { (1) } \\
\text { Capacity } \\
\text { unit }\end{array}$ & $\begin{array}{l}\text { Price } \\
\text { (at which product } \\
\text { can be sold) }\end{array}$ & $\begin{array}{l}\text { Fuel } \\
\text { cost }\end{array}$ & $\begin{array}{l}\text { (4) } \\
\text { Permits used } \\
\text { (1 permit needed for each } \\
\text { capacity unit operated) }\end{array}$ & $\begin{array}{l}\text { Price - fuel cost } \\
\text { (0 if no permit used) }\end{array}$ \\
\hline 1 st & $\$$ & $\$ 1$ & 0 or 1 \\
$2 n d$ & $\$$ & $\$ 3$ & 0 or 1 & \\
$3 r d$ & $\$$ & $\$ 5$ & 0 or 1 & \\
\hline \multicolumn{5}{l}{ Sum of price-cost differences for units operated: } \\
\hline \multicolumn{5}{l}{ Total earnings for the production period: } \\
\hline
\end{tabular}

This experiment can also be run online using the Veconlab software. ${ }^{3}$ The software provides instructions and tabulates individual decisions and earnings, with automatic graphs of observed supply functions for the class as a whole, for the person with the highest earnings, and for the person with the lowest earnings. Since this is an individual decision experiment, it can either be run 'after hours' with students logging in from home, or in class with students who bring laptops to class (those without laptops can sit next to those with laptops). It is not necessary to pick one person randomly to receive their earnings, but if you announce that you will do so in advance, the number of laptops in class will increase dramatically. The online version also permits a wide array of setup options. In particular, there can be a second 'treatment' without grandfathering (that is, where all permits are purchased at their market value of \$3) in which observed behaviour typically conforms more closely to the theoretical supply curve.

To run the online version, you need to have internet connections, but no add-ins or special software is required. The instructor should begin by navigating to the admin menu (Google 'Veconlab admin'). If not done previously, the instructor should register and select a username and password. Students do not need to register, but when they join a session they will be assigned an identification (ID) number. The instructor username consists of several letters, e.g.'cat', and each separate'session' you run with a class will have a number appended, e.g. cat 1, cat $2, \ldots$. Then select the Markets menu and click on Production Cost, to begin setup. Enter your username and password, and you see a list of sessions (if any) that you have run with previous classes.

On the first setup page, you enter the maximum number of participants (its OK if fewer login) and the following selections: Number of Treatments (2), Product Market (fixed price, NOT BDM), Number of Capacity Units (3), Terminology (environmental), Entry Decision (automatic), Input A Variable Cost (deterministic), Input B Price (deterministic), Input C Cost (deterministic), Product Prices (prespecified). It is best to keep with the default setting of 'go at your own pace' and to let people see others' earnings, identified by ID, in the second half of each treatment. There are three capacity units with fuel costs that match those for the hand run version above. Leave capacity costs set at $\$ 0$, with a forced entry decision (meaning that their capacity is given), so that the automatic supply function graphs will apply. Product prices are set in 50-cent intervals to span the relevant range. These default settings implement a two-treatment setup with eight decision rounds each. In treatment 1, the student is endowed with two permits, so a third must be purchased at $\$ 3$ if three units are operated, and unused permits can be sold for $\$ 3$. In the second treatment, the permit endowments are set at 0 .

It is convenient to set up the experiment before going to class. In the classroom, the View link on the admin menu can be used to enter the session name (e.g.cat1) and the administrative password to get to the results pages in the classroom. Students log in from the top button on their login link (Google 'Veconlab login'); all they need to know is the session name (e.g. cat1) that was used in the setup. Students may select their own passwords that would only be needed in the event that they become disconnected and need to use the Emergency Restart button at the bottom of their login page. ${ }^{4}$

As decisions are made, the results page shows the 'efficiency' percentages of maximum earnings for each person's decisions and the average efficiency by round. The graph page allows one to show or hide the supply function, and to show results for specific individuals by using the Show ID button and selecting the individual by ID. 5 When a student has finished all rounds, the Show ID select menu lists earnings and identifies the IDs with the minimum and maximum earnings.

\section{Classroom discussion}

Students are typically interested in who earned the most, and a class discussion can begin with a discussion of relative earnings. If the class default settings are used, the Graph page of the Veconlab software has a select menu that lists all participant IDs 
Figure 1: Supply decisions with grandfathering of a student with low earnings

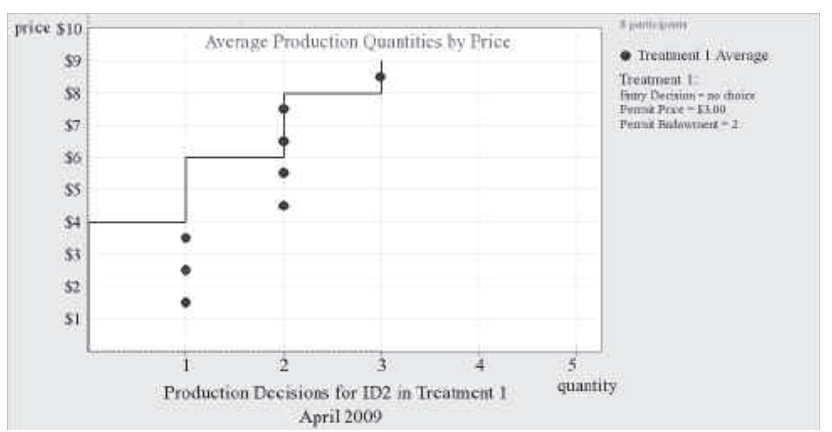

and their earnings, with the minimum and maximum earnings identified. You can connect your computer to a projector in order to share the results with the class. This lets you project the supply behavior of selected individuals for each treatment, as shown in Figure 1 for a particular student (ID2) for the first treatment. This student had the lowest overall earnings for a group of intermediate microeconomics

students. This person consistently supplied too many units to the market, as indicated by the dots below the supply function that incorporates the opportunity cost of the grandfathered permits. Of the three dots on the predicted supply function, two were at prices of $\$ 7.50$ and $\$ 8.50$, for which both of the grandfathered permits should be sold anyway, even if one failed to incorporate opportunity cost. Overall, this student only earned $\$ 60.50$, relative to the maximum earnings of $\$ 83$ achieved by those with the highest earnings. One of the most effective points to make in the class discussion is that a correct accounting for opportunity cost could have raised earnings by over $33 \%$ for this person. The decisions for the person with the highest earnings will typically generate dots that trace out the predicted supply curve.

It is often easier to let students 'go at their own pace' in a classroom experiment of this type, but the result is that the relative earnings information is not available to the first person who makes each decision, and even the second and third people to finish may not see many other earnings results with which to make comparisons.

Nevertheless, class discussion indicates that relative earnings can help some people realise that units should not be sold below the sum of the fuel cost and the opportunity cost of a permit.

The initial allocation of permits in the European Union Emissions Trading Scheme (EU ETS) for $\mathrm{CO} 2$ emissions provides an illustrative example for class discussion. Note that when opportunity cost is included correctly, the supply function is the same, whether or not permits are grandfathered. When the initial allocation for the EU ETS program was being discussed, one argument put forward by electric power producers was basically: 'if you make us pay for permits, we will end up raising the price for electricity. The instructor should read this argument to the students and ask them to evaluate it. If they have understood the implications of their experiment, they should conclude that the price of electricity will rise regardless of whether allocations are free (grandfathering) or made by selling permits. This is because the scarcity of permits results in a positive price for permits in the resale market, and this price is the basis of the opportunity cost of a permit. Then ask them to evaluate the alternative of grandfathering versus permit sales on producer profits (you may want to report the average earnings in each experimental treatment if two treatments were used).

Finally, the instructor can note that the EU initially adopted a policy of grandfathering, with auctions limited to at most $5 \%$ of permits for each country. This resulted in 'windfall profits' for producers, at least while permits remained scarce, and the result was some public dissatisfaction with the cap and trade system. Ensuing criticisms have led the European Commission to reconsider the use of free allocation. Plans are in place to auction most of the permits that will be used by the power sector beginning in 2013 transitioning to a full auction by 2020, and to auction to most other covered emission sources by 2020. The choice between free allocation and auctioning of emission permits also has emerged as a key feature of legislative proposals for climate policy in the United States. President Obama's first proposed budget plan included revenues that would result from auctioning a majority of the permits under $\mathrm{CO}_{2}$ cap and trade programme. In contrast, the leading proposals in the U.S. House of Representatives (the American Clean Energy and Security Act, HR 2454) and in the U.S. Senate (the Clean Energy Jobs and American Power Act, S.1733) would auction only a small portion of the permits in the first decades of a cap and trade programme, and give away a majority of the permits for free. 6

\section{Extensions}

Empirical analyses show that there has been significant 'pass through' of emissions permit costs in relatively competitive EU electricity markets. Bunn and Fezzi (2007) found that consumers in the UK electricity market pay for a significant portion of the value of emissions permits that industry has mostly received for free. Fell (2010) analysed the Nordic electricity market and had similar findings.

In several cases, EU governmental authorities have taken action against firms for passing through too much of the economic value of the permits given to them for free. The German Federal Cartel Office (Bundeskartellamt) sent a 'warning letter 7 to RWE 8 in 2006 charging that its industrial electricity prices were abusive because the company had passed on more than 25 per cent of the $\mathrm{CO} 2$ emission permit value 
to electricity prices. More recently, the Belgian energy market regulator, CREG, stated authorities 'must act to prevent utilities from making windfall profits by passing on the cost of carbon emission rights to consumers,' citing a finding that Belgian energy producers made close to 1.2 billion euros between 2005 and 2007 by charging customers for permits that they had received for free. ${ }^{9}$ The intuition that free allocation will not raise direct costs of production and therefore should not lead to higher consumer prices appears to be deeply ingrained in some members of the public, policy makers, and industry.

Wråke et al. (2010) use an individual choice experimental setup similar to the one described above to investigate understanding of opportunity cost in an emissions permit market. They find that many participants do not recognise opportunity costs initially, but that they learn over time and that learning can be accelerated by relative profit information. An interesting extension in the paper was the administration of a Cognitive Reflection Test (CRT) at the end of the experiment. According to Frederick (2005), the test measures 'cognitive reflection'-the ability or disposition to resist reporting the response that first comes to mind'. Wråke et al. (2010) find that those that earned higher profits in the experiment also performed better on the cognitive reflection, highlighting that the concept of opportunity cost is intuitively difficult and not initially obvious to some observers.

Classroom experiments can be illustrative for learning about market failures and externalities. Anderson and Stafford (2000) describe a classroom experiment that uses an emissions trading scheme with a double auction. Students learn that the initial allocation of property rights will not affect the efficiency of the programme, but will have dramatic effects on the distribution of gains and losses. Kilkenny (2000) outlines a classroom experiment that illustrates the concept of externalities and the efficiency tradable permits relative to Pigouvian taxes for internalising those costs. She suggests a creative way to demonstrate pollution externalities where students that have been affected wear bags on their heads. Another useful classroom exercise is to present students with an array of costs and abatement opportunities in order to explain how the demand for emissions permits is derived from profit maximising behaviour. See Weber (2002) for a careful discussion of the supply and demand schedules for permits in a cap and trade environment.

In the experiment we describe here, students make production quantity decisions based on a fixed market price. The experiment could equivalently be run where students specify the lowest price they would be willing to accept for each production unit. As with the quantity choice environment, the market price is randomly determined. Students receive the market price for production units where their specified price is below the market price. This mechanism is known as
Becker-DeGroot-Marshak (BDM) (Becker et al., 1964). Bidding along the price dimension rather than the quantity dimension is more directly analogous to electricity pricing. However, it is sometimes difficult for students to recognise that the BDM mechanism is incentive compatible and it can detract from the true goal of the lesson, which is to understand opportunity cost.

As with the notion of opportunity costs, sunk costs can also be difficult for students in beginning and intermediate micro classes to account for correctly in production decisions. An interesting extension of the experiment described in this paper would be to run treatments where there is a cost to enter the market (the setting for this is 'Entry Decision'). Both experiments with sunk costs and BDM price mechanism are available using the same Veconlab software described above.

\section{References}

Anderson, L.R. and S.L. Stafford. 2000.'Choosing Winners and Losers in a Classroom Permit Trading Game.' Southern Economic Journal, 67(1):212-19.

Becker, G., M. DeGroot and J. Marschak. 1964.'Measuring Utility by a Single-Response Sequential Method'. Behavioral Science 9:226-232.

Bunn, D.W. and C. Fezzi. 2007.'Interaction of European Carbon Trading and EnergyPrices'. The Fondazione Eni Enrico Mattei Note di Lavoro Series. Fondazione Eni Enrico Mattei, 63.2007.

Fell,H. 2010.'EU-ETS and Nordic Electricity:A CVAR Analysis'.The Energy Journal, 31(2): 219-239.

Frederick, S. 2005.'Cognitive Reflection and Decision Making'. Journal of Economic Perspectives 19(4): 25-42.

Kilkenny, M. 2000.'A Classroom Experiment About Tradeable Permits,' Review of Agricultural Economics 22(2): 586-606.

Wråke, M., E. Myers, S. Mandell, C. Holt and D. Burtraw. 2010.'Opportunity Cost for Free Allocations of Emissions Permits: An Experimental Analysis'. Environmental and Resource Economics, 46(3):331-336.

Weber, D. 2002.'Pollution Permits; A Discussion of Fundamentals'. Journal of Economic Education 33(3): 277-290.

\section{Notes}

1 Work on this project was funded in part by the National Science Foundation (SBR 0094800), the US Environmental Protection Agency, and Mistra's Climate Policy Research Program (CLIPORE).

2 Students should be aware that the term 'allowance' is used instead of 'permit' in many discussions and regulations.

3 This 'virtual laboratory' software was developed by Charles Holt at the University of Virginia.

4 If the back arrow is used to adjust settings, students who have already logged in will have to do so again, so it is better to check the instructions and graph before class. 
5 With the suggested setup defaults, the graph should show the template for a supply function; if not, it is probably because you did not set the Product Market to be'fixed price' or because you changed the capacity cost or entry settings.

6 Free allocation in these proposals is achieved in a variety of ways including grandfathering to emitters and also to regulated local distribution companies, which are expected (with regulatory oversight) to pass on the opportunity cost of the permits to consumers.

7 See press release 20 December 2006, URL:

www.bundeskartellamt.de/wEnglisch/News/Archiv/ArchivNews2006/2006_12_20.php

8 RWE is one of the largest electricity producers in Germany. RWE is subject to the EU ETS and, as all entities participating in EU ETS, has received a major share of their

permits for free according to a grandfathering procedure.

9 As quoted by Thompson Reuters, 21 January 2009.

\section{Contact details}

Charles Holt

Economics

University of Virginia

Charlottesville

VA 22904-4188

Email: holt@virginia.edu

Erica Myers

University of California

Berkeley

Email: ericamyers@rff.org

Dallas Burtraw

Resources for the Future

Washington DC

Email: burtraw@rff.org

Markus Wråke

IVL Swedish Environmental Institute

Stockholm

Sweden

Email: markus.wrake@ivl.se

Svante Mandell

VTI Swedish National Road and Transport Institute

Stockholm

Sweden

\section{Do Classroom Experiments Affect the Number of Economics Enrolments and Majors? A Study of Students in the United States}

Tisha L. N. Emerson and Beck A. Taylor

\begin{abstract}
The present study follows a cohort of 290 students, at an American university, who were exposed to two different pedagogical approaches - traditional 'chalkand-talk' and classroom experiments. Although we find that the number of majors and upper division economics classes taken were not significantly different between the two groups as a whole, there were some differences across individual characteristics. For example, males who were exposed to classroom experiments enrolled in more upper division economics courses than similar males in the control group. Also, students in the experimental group who had taken economics in high school enrolled in more upper division economics courses than their counterparts in the control group. Minorities in the experimental group, however, enrolled in fewer upper division economics classes than their colleagues in the control group.
\end{abstract}

\section{Introduction}

In the United States, between 1950 and 1998 the proportion of bachelors degrees awarded in economics fell nearly 60 per cent from a high of 3.4 per cent of all degrees to a low of 1.4 per cent (Becker 2001). More recently, this decline has ebbed with considerable growth in the major in the late 1990s and early 2000 s when virtually the entire decline of the early 1990s (some 27 per cent) was reversed by 2003. The

number of economics degrees awarded between 2005 and 2007 changed little, but 